\title{
Microscopic trans-cerebellar approach for infratentorial cavernous malformation near the lateral recess associated with developmental venous anomaly. Case report
}

\author{
Samer S. Hoz ${ }^{1}$, Awfa A. Aktham², Hassan M. \\ Bdaiwi ${ }^{3}$, Alyaa A. Khadim², Zainab A. Jihan², \\ Mohammed Maan AbdulAzeez ${ }^{4}$
}

1 Neurosurgeon, FRCS Neurosurgery Glasgow, Department of Neurosurgery, Neurosurgery Teaching Hospital, Baghdad, IRAQ

2 Neurosurgery resident, Department of Neurosurgery, Neurosurgery Teaching Hospital, Baghdad, IRAQ

3 Neurosurgeon, Department of Meurosurgery, Alramadi Teaching Hospital, Anbar, IRAQ

4 Medical Student, University of Baghdad, College of Medicine, Baghdad, IRAQ

\section{ABSTRACT}

Background: Reports showed the intimate association of the developmental venous anomaly with infra-tentorial cavernous malformation. This association has several clinical and surgical implications, sometimes this association will be a surgical challenge and affect the selection of the safest approach to the lesion. Surgery for infratentorial cavernoma is indicated for accessible symptomatic lesion only.

Case scenario: we present a case of deep cerebello-pontine CM adjacent to the lateral recess, presented with acute clinical deterioration to the emergency department of the Neurosurgery Teaching Hospital in Baghdad, Iraq, with the only possible approach was Trans-cerebellar approach because of the medial location of the associated DVA.

Conclusion: The association of developmental venous anomaly with infratentorial cavernous malformation has a pivotal role in selection the most appropriate and safe surgical approach which should be based upon the individualized patient anatomy and the location of the target lesion.

\section{INTRODUCTION}

Developmental venous anomaly is also called venous angiomas, although the latter is abandoned at time being (1). DVA drains normal brain tissue, and its formation is still controversial, with most studies suggest that DVA represent an arrested development of primitive

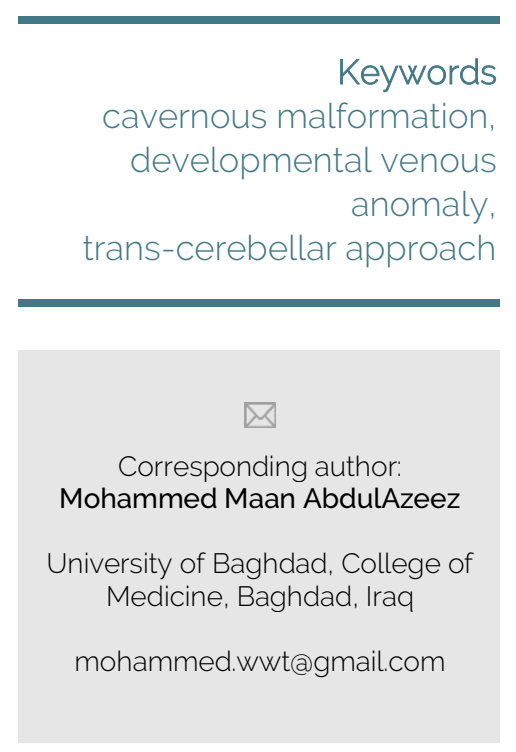

Copyright and usage. This is an Open Access article, distributed under the terms of the Creative commons Attribution Non-Commercial No Derivatives License (https://creativecommons org/licenses/by-nc-nd/4.0/) which permits noncommercial re-use, distribution, and reproduction in any medium, provided the original work is unaltered and is properly cited

The written permission of the Romanian Society of Neurosurgery must be obtained for commercial re-use or in order to create a derivative work.

ISSN online 2344-4959 (C) Romanian Society of Neurosurgery

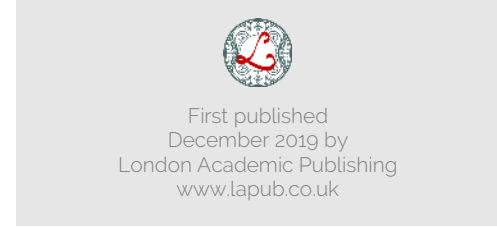


medullary venous system (1). Other emerging studies suggesting the acquired nature of this vascular lesion with possible causation of the associated $\mathrm{CM}$ by alteration of the local hemodynamics $(2,3)$.

Before the introduction of brain CT scan and brain MRI, the association between developmental venous anomaly (DVA) and cavernous malformation (CM) was not well established. The initial report was at 1984 after introduction of CT scan then followed by frequent reports supporting and confirm this association especially when the brain MRI included as a common investigating tool for intracranial vascular lesions (4-6). Recent reports showed that up to $30 \%$ of DVA are associated with CM, and up to $100 \%$ of CM are intimately associated with DVA (710).

The MRI features of the CM include the classic "popcorn appearance" due to the presence of hemorrhages at different ages. The DVA are usually angiographically evident in the form of the classic caput medusa and may be very clear on MRI also especially when being large in size. Developmental venous anomalies may be visible only after excision of the associated CM (10).

Surgery for infratentorial cavernoma is indicated for accessible symptomatic lesion only.

We present a case of deep cerebello-pontine CM adjacent to the lateral recess with the only possible approach was Trans-cerebellar approach because of the medial location of the associated DVA.

\section{CASE SCENARIO}

A twenty-nine years old male, a known case of CM, presented to the emergency department of the neurosurgery teaching hospital, Baghdad, Iraq, with acute onset of drowsiness, left side ataxia and cerebellar signs, nystagmus with previous two mild attacks. Imaging revealed a new and larger deep cerebello-pontine hemorrhage as compared with previous imaging, the MRI suggest confirmation of the previous diagnosis as hemorrhagic cavernoma, associated with very large DVA that runs medial then superior to the CM to be drained into the Galenic venous system, with no hydrocephalus (Figure $1 \mathrm{~A}, 1 \mathrm{~B})$. Based on the acute presentation, the location and size of the hematoma, the history of recurrent hemorrhages, we decide to evacuate the hematoma urgently. With the patient in prone position, left trans-cerebellar approach was done through left suboccipital craniectomy, the hematoma and the CM are totally removed using microsurgical technique. The associated DVA is preserved to avoid any unwanted events. The patient improved gradually over the first 5 days' post operatively and discharged home 10 days after the admission with significant improvement. Three months follow up MRI show the complete evacuation of the $\mathrm{CM}$ with preservation of the adjacent DVA. The patient was conscious, neurologically intact apart from very mild ataxia of the left side on follow up visits (Figure 1C).

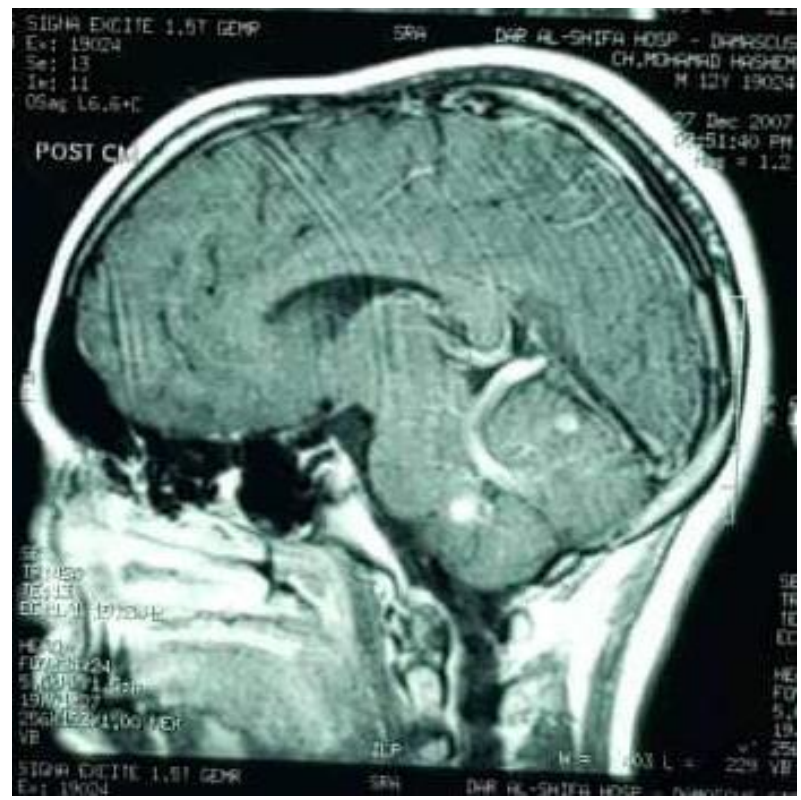

A

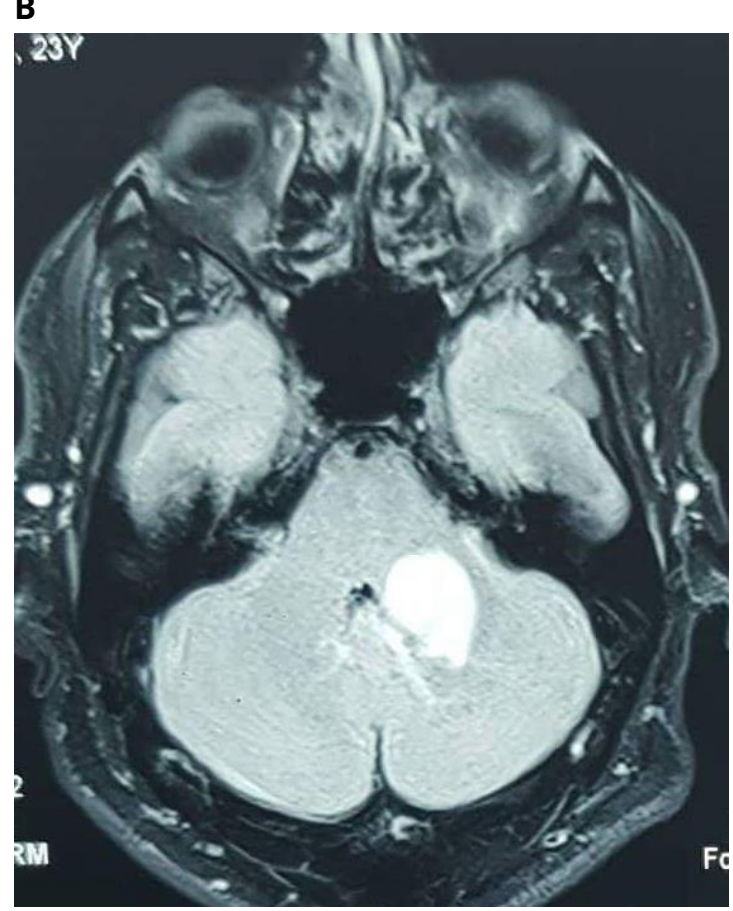




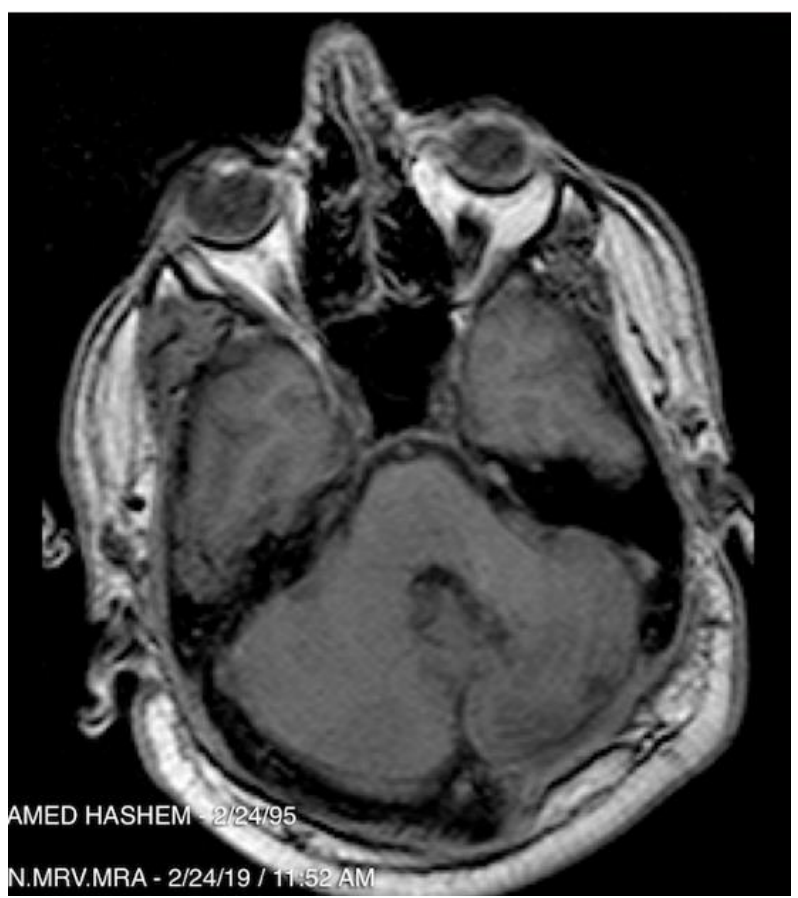

C

Figure 1: Deep cerebello-pontine hemorrhagic CM associated with very large DVA that runs medial then superior to the CM to be drained into the Galenic venous system, with no hydrocephalus. pre-operative sagittal (A) and axial (B) MRI with contrast, showed both the CM and the large DVA. (C): postoperative axial T1 MRI, showed the resection cavity.

\section{DISCUSSION}

The usual surgical approaches for infratentorial CM near the lateral recess include trans-lateral recess telovellar approach, transcerebellomedullary fissure approach, presigmoid approach, or rarely the anterior endoscopic approach $(11,12)$. The presence of a DVA associated with the CM may render the common approaches not feasible. Our case of cerebello-medullary CM adjacent to the lateral recess with the only possible approach was Trans-cerebellar approach because of the medial location of the associated DVA.

The surgical strategy for infratentorial CM involves two critical goals:

1. CM should be totally excised to prevent the risk of recurrent hemorrhages without affecting the surrounding normal parenchyma.

2. Extreme care should be taken to preserve the associated DVA to prevent venous disasters to the normal brain tissue.

Thus, the usual approach that should be preferred according the accessibility of the CM, will be greatly affected by the location of the associated DVA. the usual entry zones may be disturbed by the overlying vascular tissue. Although there are frequent reports showed that coagulating some parts of the DVA when mandatory during surgery of $\mathrm{CM}$, may pass peacefully especially if the DVA is already detected in the preoperative imaging and considered during presurgical planning $(10,13)$. To note that till now there is no approved research comparing DVA resection against DVA preservation during CM resection surgery $(10,14,15)$.

Although the trans-cerebellar approach is not always a preferable approach as it involves transgression of important anatomical structure especially deep cerebellar nuclei, but in this case, the advantage of hematoma evacuation outweighs other disadvantages. Also, the use of meticulous microsurgical technique with good planning that take in consideration the anatomical landmarks and the possible obstacles, this approach remain a viable option particularly when other approaches are not possible or not safe.

\section{CONCLUSION}

The association of developmental venous anomaly with infratentorial cavernous malformation has a pivotal role in selection the most appropriate and safe surgical approach which should be based upon the individualized patient anatomy and the location of the target lesion.

Abbreviations list:

CM: Cavernous Malformation

DVA: Developmental Venous Anomaly

CT: Computerized Tomography

MRI: Magnetic Resonance Imaging

Funding information:

Nothing to declare.

Conflict of Interest declaration:

Nothing to declare.

\section{REFERENCES}

1. Lasjaunias $P$, Burrows $P$, Planet $C$. Developmental venous anomalies (DVA): the so-called venous angioma. Neurosurgical review. 1986 Sep 1;9(3):233-42.

2. Comey $\mathrm{CH}$, Kondziolka $\mathrm{D}$, Yonas $\mathrm{H}$. Regional parenchymal enhancement with mixed cavernous/venous malformations of the brain: Case report. Journal of neurosurgery. 1997 Jan 1;86(1):154-8. 
3. Rothbart D, Awad IA, Lee J, Kim J, Harbaugh R, Criscuolo GR. Expression of angiogenic factors and structural proteins in central nervous system vascular malformations. Neurosurgery. 1996 May 1;38(5):915-25.

4. TAKAMIYA Y, TAKAYAMA H, KOBAYASHI K, MINE T, SUZUKI $\mathrm{K}$. Familial occurrence of multiple vascular malformations of the brain. Neurologia medico-chirurgica. 1984;24(4):2717.

5. Rigamonti D, Spetzler RF. The association of venous and cavernous malformations. Acta neurochirurgica. 1988 Mar 1;92(1-4):100-5.

6. Wilms G, Bleus E, Demaerel P, Marchal G, Plets C, Goffin J, Baert AL. Simultaneous occurrence of developmental venous anomalies and cavernous angiomas. American journal of neuroradiology. 1994 Aug 1;15(7):1247-54.

7. Abdulrauf SI, Kaynar MY, Awad IA. A comparison of the clinical profile of cavernous malformations with and without associated venous malformations. Neurosurgery. 1999 Jan 1;44(1):41-6.

8. Marasco R, Spagnoli M, Leonardi M. Association between developmental venous anomalies and cavernous angiomas: a retrospective MR study. The neuroradiology journal. 2009 Apr;22(2):179-85.

9. Perrini $P$, Lanzino $G$. The association of venous developmental anomalies and cavernous malformations: pathophysiological, diagnostic, and surgical considerations. Neurosurgical focus. 2006 Jul 1;21(1):1-4.
10. Porter RW, Detwiler PW, Spetzler RF, Lawton MT, Baskin JJ, Derksen PT, Zabramski JM. Cavernous malformations of the brainstem: experience with 100 patients. Journal of neurosurgery. 1999 Jan 1;90(1):50-8.

11. Akiyama, O., Matsushima, K., Nunez, M., Matsuo, S., Kondo, A., Arai, H., Rhoton, A.L. and Matsushima, T., 2018. Microsurgical anatomy and approaches around the lateral recess with special reference to entry into the pons. Journal of neurosurgery, 129(3), pp.740-751.

12. Deshmukh VR, Rangel-Castilla L, Spetzler RF. Lateral inferior cerebellar peduncle approach to dorsolateral medullary cavernous malformation. Journal of neurosurgery. 2014 Sep 1;121(3):723-9.

13. Wurm G, Schnizer M, Fellner FA. Cerebral cavernous malformations associated with venous anomalies: surgical considerations. Operative Neurosurgery. 2005 Jul 1;57(suppl_1):42-58.

14. Pozzati E, Marliani AF, Zucchelli M, Foschini MP, Dall'Olio M, Lanzino G. The neurovascular triad: mixed cavernous, capillary, and venous malformations of the brainstem. Journal of neurosurgery. 2007 Dec 1;107(6):1113-9.

15. Pereira VM, Geibprasert S, Krings T, Aurboonyawat $T$, Ozanne A, Toulgoat F, Pongpech S, Lasjaunias PL. Pathomechanisms of symptomatic developmental venous anomalies. Stroke. 2008 Dec 1;39(12):3201-15. 